\title{
BACIAS HIDROGRÁFICAS E GESTÃO DOS RECURSOS HÍDRICOS: O CASO DA REGIÃO HIDROGRÁFICA ATLÂNTICO LESTE
}

\author{
Hydrographic basin and hydrical resources management: the case of East Atlantical \\ Hydrographic Region
}

\section{Cuencas hidrográficas y gestión de los recursos hídricos: el caso de la Región Hidrográfica Atlántico Este}

\author{
Andrevânia Santos de Matos ${ }^{1}$ https://orcid.org/0000-0003-0695-908X \\ Cleudes Rodrigues Rocha ${ }^{2}$ https://orcid.org/0000-0002-8899-1616 \\ Manoel Alves de Oliveira ${ }^{3}$ http://orcid.org/0000-0001-5220-2593
}

\footnotetext{
${ }^{1}$ Graduanda em Licenciatura Plena em Geografia na Universidade do Estado da Bahia - UNEB, Campus VI, Caetité-BA, email vaniamatoss1@ hotmail.com

${ }^{2}$ Graduando em Licenciatura Plena em Geografia na Universidade do Estado da Bahia - UNEB, Campus VI, Caetité-BA, email cleudescte@hotmail.com

${ }^{3}$ Doutor em Geografia pela Universidade Federal Fluminense. Professor Adjunto da Universidade do Estado da Bahia - UNEB, Campus VI, Caetité-BA, email mano.geografia@gmail.com
}

\section{Resumo}

Este trabalho tem por objetivo discutir sobre a Região Hidrográfica Atlântico Leste, considerando a importância da gestão e preservação dos recursos hídricos no que se refere à demanda e disponibilidade de água. Para isso, realizou-se pesquisa bibliográfica de caráter qualitativo com base em Garcez e Alvarez (1988), Oliveira (2012) e Paula et al. (1997). O estudo também apresenta perfil documental, tendo como suporte a Política Nacional de Recursos Hídricos (Lei $\mathrm{n}^{\circ}$ 9.433/1997), documentos oficiais do Governo Federal, a Agência Nacional de Águas, o Ministério do Meio Ambiente e a Secretaria de Recursos Hídricos. Os resultados obtidos contribuíram para a caracterização da referida região hidrográfica com ênfase nos aspectos voltados para a demanda, disponibilidade e conflitos pela água nos setores que fazem uso consuntivo do recurso.

Palavras-chave: Atlântico Leste. Gestão. Recursos hídricos.

\begin{abstract}
This work aims to discuss about the East Atlantical Hidrographic Region, considering the importance of the management and preservation of the hidrical resources refering to the demand and availability water. For this, it was used a bibliographical research of qualitative character with basis in Garcez and Alvarez (1998), Oliveira (2012), Paula et al. (1997). The study also represents documental profile, as suport the Hidrical Resources of National Political (Law no 9.433/1997), oficial documents of Federal Government, Water National Agency, Environment Ministery and Hidrical Resources Secretary. The results achieved contributed to the charactetization of the East Atlantical hidrographical region with focus in the aspects related to the demand, availability and conflicts by the water in the sector that do use consumed of the resource.
\end{abstract}

Key words: East Atlantical. Management. Hidrical resources. 


\section{Resumen}

Este trabajo tiene por objetivo discutir sobre la Región Hidrográfica Atlántico Este, considerando la importancia de la gestión y preservación de los recursos hídricos en lo que se refiere a la demanda y disponibilidad de agua. Para ello, se realizó una investigación bibliográfica de carácter cualitativo con base en Garcez y Alvarez (1988), Oliveira (2012) y Paula et al. (1997). El estudio también presenta perfil documental, teniendo como soporte la Política Nacional de Recursos Hídricos (Ley $\mathrm{n}^{\circ} 9.433$ / 1997), documentos oficiales del Gobierno Federal, la Agencia Nacional de Aguas, el Ministerio de Medio Ambiente y la Secretaría de Recursos Hídricos. Los resultados obtenidos contribuyeron a la caracterización de la referida demarcación hidrográfica con énfasis en los aspectos volcados hacia la demanda, disponibilidad y conflictos por el agua en los sectores que hacen uso consuntivo del recurso.
\end{abstract}

Palabras clave: Atlántico oriental. Gestión. Recursos hídricos.

\title{
Introdução
}

A água é um elemento de suma importância para a existência da vida no planeta Terra. No entanto, ela está distribuída de forma desigual entre os continentes, o que gera problemas ligados, principalmente, ao acesso e gestão do recurso. O Brasil possui uma situação confortável no que se refere aos recursos hídricos, no entanto, a distribuição espacial desses recursos no território brasileiro é desigual (ANA, 2013), isso porque há regiões que possuem maior disponibilidade hídrica do que outras de acordo às condições climáticas e localização das bacias hidrográficas.

O Brasil está dividido em doze regiões hidrográficas (ANA, 2002), as quais abrangem determinados Estados e suas bacias. Essa divisão permite um melhor gerenciamento das águas, uma vez que é possível caracterizar as regiões com base nos seus aspectos físicos, climáticos, demográficos, entre outros, estabelecendo relações entre os recursos hídricos, sua disponibilidade e distribuição para os usos consuntivos.

Nesse sentido, o presente estudo objetiva discutir sobre a Região Hidrográfica Atlântico Leste, considerando a importância da gestão e preservação dos recursos hídricos no que se refere à demanda e disponibilidade de água. Para isso, fez-se necessária a realização de uma pesquisa de caráter qualitativo através de revisão bibliográfica e análise documental, a qual permitiu identificar diversas características da área de estudo, bem como aspectos voltados à implantação de políticas para regulamentar a utilização dos recursos hídricos da região através de órgãos competentes. 
Bacias hidrográficas e gestão dos recursos hídricos: o caso da Região Hidrográfica Atlântico Leste MATOS, A. S. de; ROCHA, C. R.; OLIVEIRA, M. A. de

As principais motivações para a realização desta pesquisa estão vinculadas ao interesse em saber sobre questões de demanda e disponibilidade dos recursos hídricos nessa região hidrográfica. Os conhecimentos adquiridos podem servir para informação e para o desenvolvimento de novas pesquisas, pois avaliamos que é necessário, para complementação deste estudo, a realização de trabalhos de campo, observações empíricas e catalogação de dados a respeito dos usos e preservação da água na região, observando a aplicação de políticas públicas e comitês de bacias.

Nessa perspectiva, o estudo aqui apresentado se subdivide em dois tópicos, o primeiro apresenta questões voltadas ao conceito de bacia hidrográfica e à metodologia do trabalho; o segundo traz aspectos relacionados à divisão do Brasil em regiões hidrográficas e à importância das políticas públicas e comitês de bacias para a gestão dos recursos hídricos. Em seguida, apresentam-se a caracterização e discussão dos resultados obtidos sobre a região hidrográfica pesquisada.

\section{Material e métodos}

As bacias hidrográficas são muito importantes para o estudo dos recursos hídricos, pois comportam elementos físicos, ambientais e sociais, que viabilizam o entendimento de aspectos como a demanda, disponibilidade, gestão e democratização das águas, os quais se configuram em questões constantemente discutidas na atualidade, visto que em grande parte das bacias e regiões hidrográficas surgem conflitos relacionados aos usos da água.

Para compreender tais aspectos é necessário levar em consideração as principais características de uma bacia hidrográfica, os atributos topográficos, fluviomorfológicos, geológicos, vegetais, térmicos, hidrológicos (GARCEZ e ALVAREZ, 1988). Também os elementos ligados à ação antrópica, resultados da relação homem-natureza, e as influências referentes à legislação, que dispõe de indicativos relacionados, por exemplo, à preservação e gerenciamento dos recursos hídricos.

Pode-se definir bacias hidrográficas como "sistemas terrestres e aquáticos geograficamente definidos, compostos por sistemas físicos, econômicos e sociais, onde se conjugam questões ambientais" (PAULA, et al, 1997, p. 257).

Sinteticamente, compreende-se que bacia hidrográfica pode ser definida como uma área de drenagem composta por um rio principal e seus tributários, que se comporta de acordo com a influência de um arcabouço estrutural composto por atributos físicos e humanos. Com 
Bacias hidrográficas e gestão dos recursos hídricos: o caso da Região Hidrográfica Atlântico Leste MATOS, A. S. de; ROCHA, C. R.; OLIVEIRA, M. A. de

base na Política Nacional de Recursos Hídricos (PNRH), Lei no 9.433/1997, em seu capítulo I, Art. $1^{\circ}$, inciso V, "a bacia hidrográfica é a unidade territorial para implementação da Política Nacional de Recursos Hídricos e atuação do Sistema Nacional de Gerenciamento de Recursos Hídricos".

A bacia hidrográfica, de acordo com Oliveira (2012), não é apenas um elemento de cunho natural, pois sua configuração exerce influência em diversos âmbitos sociais, principalmente por determinar questões referentes à disponibilidade de recursos hídricos. Mais do que uma área de drenagem com um rio principal e seus afluentes, a bacia hidrográfica é condicionante social e econômico, se configurando como fator determinante para a política de gerenciamento e distribuição da água entre os setores que dela fazem uso.

Nesse contexto, este trabalho de investigação constitui-se em uma pesquisa bibliográfica de caráter qualitativo. De acordo com Lakatos e Marconi (2010), esse tipo de pesquisa tem por finalidade colocar os pesquisadores em contato com aquilo que já foi registrado sobre a temática pesquisada, ou seja, permite a análise das ideias de outros autores.

A abordagem qualitativa, por sua vez, permite ao pesquisador a análise integrada do fenômeno estudado tendo em vista que, "os dados recolhidos são em forma de palavras ou imagens e não números.” (BOGDAN e BIKLEN, 1994, p.48).

Desse modo, houve a seleção de material bibliográfico, leitura, análise e fichamento das ideias centrais. As principais bibliografias utilizadas foram Garcez e Alvarez (1988), Oliveira (2012), Paula et al. (1997), que contribuíram para a composição das reflexões teóricas, trazendo abordagens a respeito do conceito de bacia hidrográfica e de região hidrográfica enquanto elementos fundamentais para a compreensão da importância da gestão dos recursos hídricos.

A metodologia utilizada também se baseia em uma pesquisa documental, na qual “[...] a fonte de coleta de dados está restrita a documentos, escritos ou não, constituindo o que se denomina de fontes primárias." (LAKATOS e MARCONI, 2010, p. 157). Para isso, se consultou a Política Nacional de Recursos Hídricos (Lei das Águas no 9.433/1997) e documentos oficiais do Governo Federal, da Agência Nacional de Águas (ANA), do Ministério do Meio Ambiente (MMA) e da Secretaria de Recursos Hídricos.

\section{Resultados e discussões}


Bacias hidrográficas e gestão dos recursos hídricos: o caso da Região Hidrográfica Atlântico Leste MATOS, A. S. de; ROCHA, C. R.; OLIVEIRA, M. A. de

Segundo a ANA (2002, p. 43), "para fins de gestão de recursos hídricos e dentro do [contexto] da Lei das Águas, divide-se o Brasil em regiões hidrográficas. Uma região hidrográfica é uma bacia ou conjunto de bacias hidrográficas contíguas onde o rio principal deságua no mar ou em território estrangeiro.” Atualmente, no Brasil são consideradas 12 regiões hidrográficas: Amazônica, Tocantins-Araguaia, Atlântico Nordeste Ocidental, Parnaíba, Atlântico Nordeste Oriental, São Francisco, Atlântico Leste, Paraguai, Paraná, Sudeste, Uruguai e Atlântico Sul (Figura 1). Neste trabalho, entretanto, concentra-se a investigação sobre a região Atlântico Leste.

Mapa 1- Regiões hidrográficas brasileiras

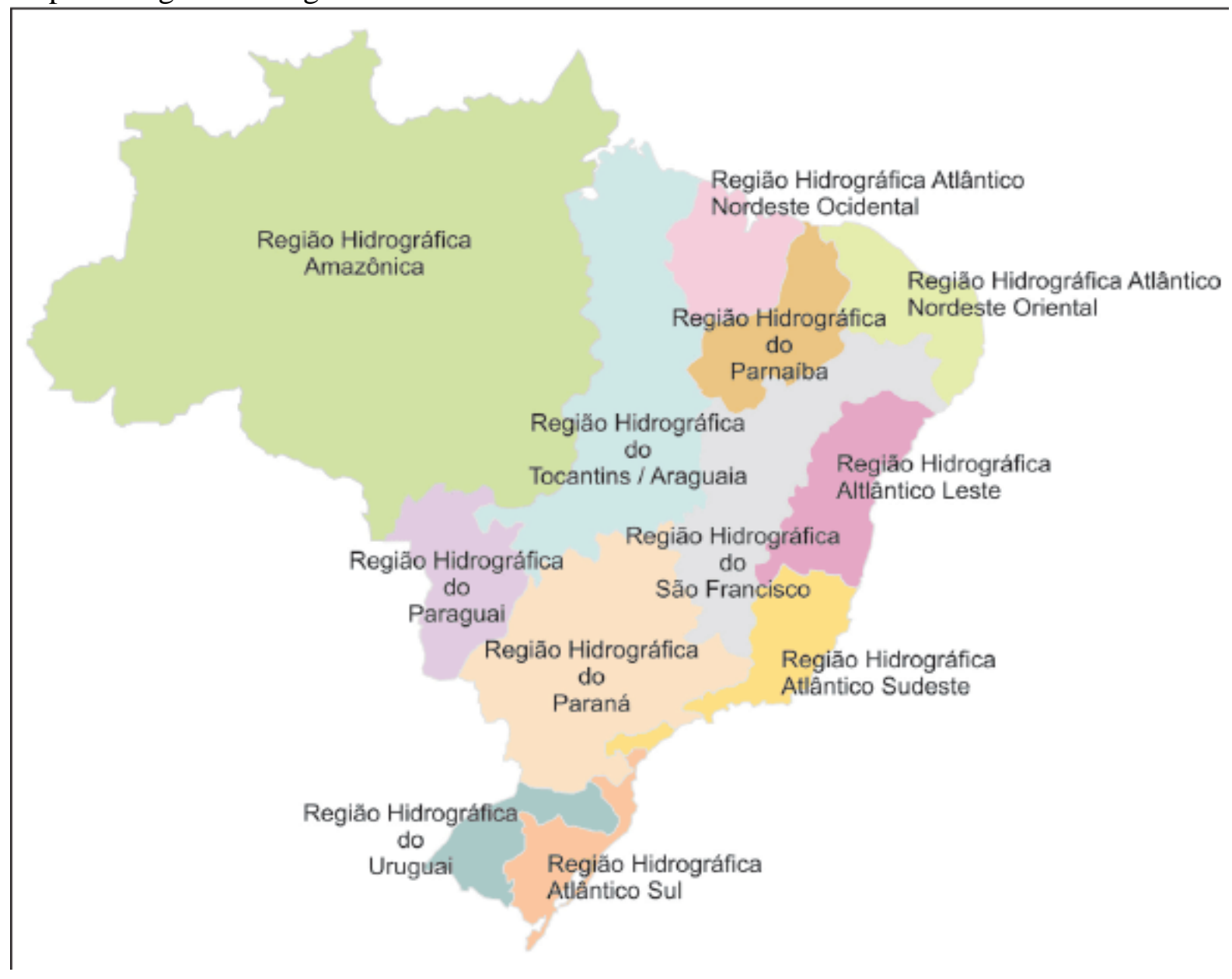

Fonte: CNRH (2003)

A distribuição das águas no Brasil acontece de forma desigual, assim algumas regiões hidrográficas possuem maior volume de água do que outras. Com isso, conflitos pelo uso da água na região do rio Amazonas, por exemplo, são limitados, pois a mesma dispõe de grande volume de água, alta vazão e baixa densidade demográfica. Já em regiões como em parte do 
Rio São Francisco, as chuvas irregulares proporcionam menor disponibilidade de água, potencializando a disputa por esse recurso (ANA, 2002).

Devido a essa irregular distribuição de água,

No Brasil, o uso dos recursos hídricos tem sido alvo de crescentes demandas dos diversos setores usuários [...]. Os potenciais conflitos resultantes dos múltiplos usos da água e os problemas ambientais têm levado a esforços para a adoção de gestão racional de seu uso, com a aplicação de instrumentos que auxiliem o desenvolvimento sustentável das bacias e das regiões hidrográficas. (ANA, 2009, p. 116).

Na legislação aplicada nesse setor, no país, o órgão máximo responsável por dirimir os conflitos pelo uso da água é o Conselho Nacional de Recursos Hídricos (CNRH), juntamente com a ANA e os Comitês de Bacias Hidrográficas $(\mathrm{CBH})$. Sobre os quais é importante considerar que,

O CNRH, órgão máximo que define a política e elabora o Plano Nacional de Recursos Hídricos, foi criado em 1998. Já a ANA, que começou a funcionar em 2001, é responsável pela implementação da Política Nacional de Recursos Hídricos (PNRH), a exemplo do apoio na implantação de Comitês de Bacias Hidrográficas ( $\mathrm{CBH})$. Os comitês constituem-se em fóruns deliberativos tripartites importantes no ato de dirimir conflitos quanto ao uso da água, definindo regras para o direito de uso de um determinado quantitativo de água [...]. (OLIVEIRA, 2012, p. 53).

Ainda de acordo com Oliveira (2012, p. 53), "a instituição de comitês de bacias é aprovada pelo CNRH, que os classificam como nacionais (quando a bacia banha mais de um estado) ou estaduais (em caso de esse sistema não ultrapassar os limites de determinada unidade da federação)". Os comitês de bacias têm grande importância na gestão dos recursos hídricos, pois atuam diretamente na bacia hidrográfica que esse representa, podendo acompanhar o cumprimento das metas das políticas públicas para a gestão e preservação dos recursos hídricos.

A Região Hidrográfica Atlântico Leste possui uma área de $386.092 \mathrm{~km}^{2}$, compreendendo os Estados da Bahia, Minas Gerais, Espírito Santo e Sergipe. De acordo com a ANA (2015), possui uma rede hidrográfica dividida em oito unidades: Vaza Barris; Litorânea BA-SE; Itapicuru; Litorânea BA, Paraguaçu; Contas; Pardo Jequitinhonha, e Litorânea ES-BA (Mapa 1). Tendo como principais rios: Vaza-Barris; Barba do Tubarão; Real; Itapicuru-açu; Itapicuru; Inhambupe; Jacuípe; Salgado; Pojuca; Capivari; Paraguaçu; 
Bacias hidrográficas e gestão dos recursos hídricos: o caso da Região Hidrográfica Atlântico Leste MATOS, A. S. de; ROCHA, C. R.; OLIVEIRA, M. A. de

São João; Salto; Gavião; Conguji; Contas; Pardo; Itacambiruçu; Araçaí; Jequitinhonha; Prado ou Jucurucu; Alcobaça ou Itanhaém; Mucuri; Cibrão e São Mateus

Um aspecto marcante na região Atlântico Leste é a compartimentação topográfica e o seu arranjo no território. Isso por que,

Topograficamente, a Região Hidrográfica Atlântico Leste encontra-se compreendida entre uma importante unidade de relevo do território brasileiro que é o orógeno do Espinhaço [...] ou como é conhecido mais comumente, a Serra do Espinhaço, cuja extensão mais setentrional assume a toponímia local da Chapada Diamantina e a planície e tabuleiros costeiros, considerando aqui a inclusão de feições menores como estuários, restingas, alagadiços e outras de pequena dimensão. A porção central é marcada por um relevo em boa parte colinoso, por vezes salpicado de pontões e/ou dorsos rochosos esculpidos em litologias cristalinas. (MMA, 2006, p. 29).

Segundo o MMA (op. cit.), a região estudada é uma área tropical, sob forte incidência da radiação solar, com clima quente e úmido, podendo ser caracterizada por quatro tipos de clima: super-úmido, úmido, semi-úmido e semiárido. Também evidencia formações naturais representadas por cinco ecorregiões: a Ecorregião da Caatinga, das Florestas Secas, das Florestas Costeiras, das Florestas Interiores e a Ecorregião da Chapada Diamantina-Serra do Espinhaço.

Parte da região Atlântico Leste localiza-se no semiárido nordestino, que possui períodos de estiagem prolongada devido aos baixos índices pluviométricos e à alta evapotranspiração (ANA, 2015), o que reflete na disponibilidade dos recursos hídricos, gerando conflitos por demanda e disponibilidade, sobretudo nas bacias do Estado de Sergipe e Itapicuru-Paraguaçu.

Além dos fatores naturais, ocorrem conflitos relacionados à pecuária, agricultura, empreendimentos turísticos, expansão urbana, entre outros, que exercem influências sobre a preservação ambiental e disponibilidade de água para os usos consuntivos, caracterizando também o uso e ocupação do solo.

Ainda de acordo ao MMA (2006), as pressões antrópicas que ocorrem nas cidades costeiras da região estão atreladas à concentração populacional, expansão urbana, concentração de indústrias e turismo, gerando esgotos, disposição imprópria de resíduos sólidos, ocupação de áreas de risco e poluição. Fatores de pressão ambiental também se destacam na região, como a silvicultura, plantio de cana de açúcar e pecuária na porção da baixa Bacia do Litoral Sul BA 01, Mucuri, Itaúnas e São Mateus, e o cultivo, geralmente irrigado, do mamão e café na porção extremo-sul. 
Bacias hidrográficas e gestão dos recursos hídricos: o caso da Região Hidrográfica Atlântico Leste MATOS, A. S. de; ROCHA, C. R.; OLIVEIRA, M. A. de

Mapa 2 - Unidades Hidrográficas da Região Hidrográfica Atlântico Leste

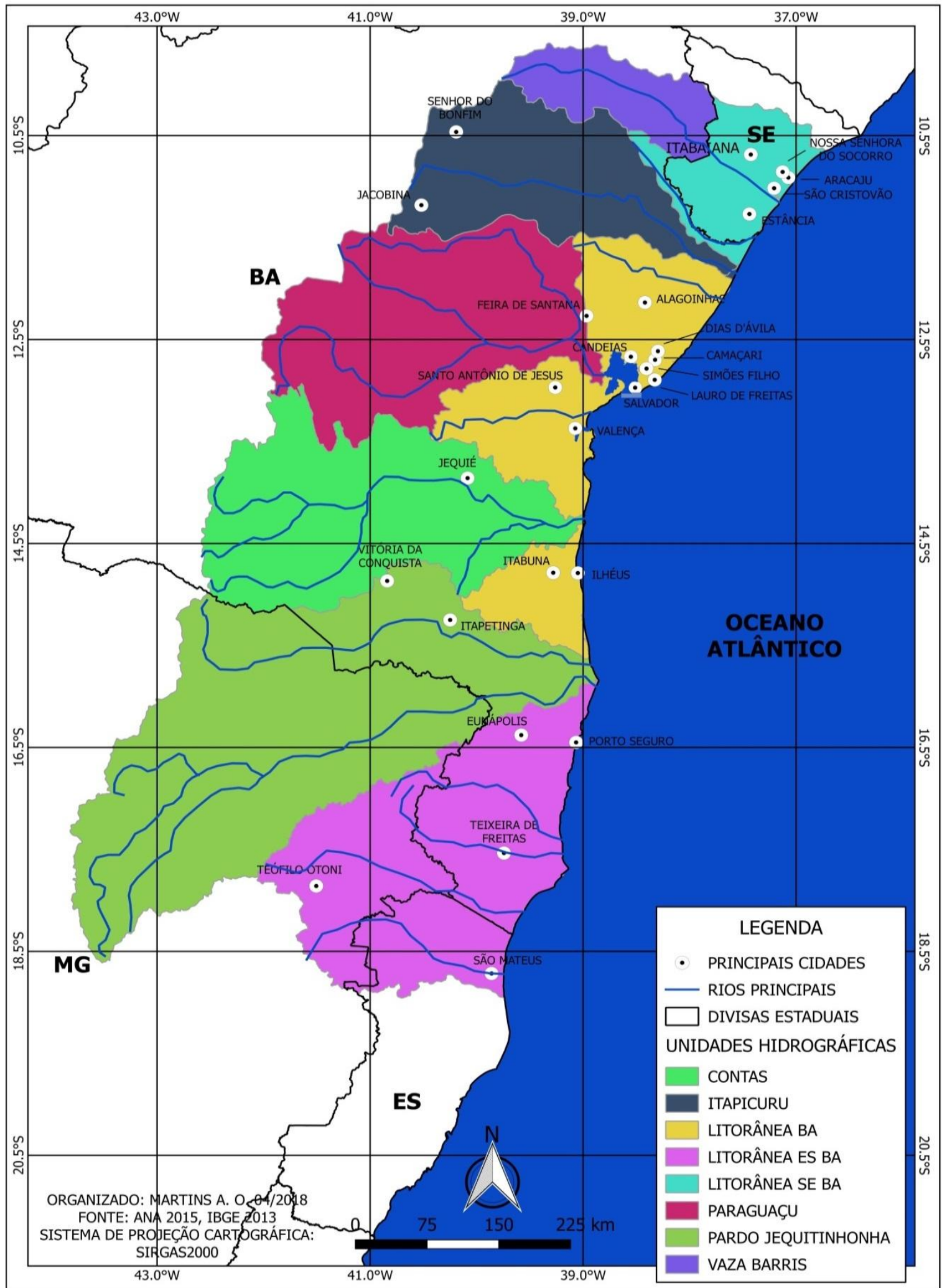

Fonte: elaborado por Martins (2018)

Essas atividades utilizam grande quantidade de água ou contribuem para o desperdício e perda da qualidade do recurso. É nesta perspectiva, dos usos consuntivos e da preservação 
dos recursos hídricos que surge a importância das políticas públicas para a gestão e democratização das águas. Para Rocha (2012), a percepção do caráter finito dos estoques hídricos contribuiu para a elaboração de uma política institucional das águas que,

[...] assume características democráticas, com a participação do poder público, dos usuários e da sociedade civil com partilhamento de processos deliberativos nas mais diversas esferas. Há que ser afirmada a necessidade de efetivação da democracia do acesso à água, com a possibilidade de acesso equitativo do bem a todas as pessoas, independentemente de condição social, etnia, gênero e geração [...]. (ROCHA, 2012, p. 111).

A região Atlântico Leste, como pode ser observado no gráfico 1, apresenta diferentes demandas por água em setores como: irrigação (47\%), abastecimento urbano (31\%), uso industrial (10\%), dessedentação animal (8\%) e abastecimento rural (4\%), gerando uma demanda total equivalente a 5\% da demanda nacional (ANA, 2013). Estes dados demonstram as necessidades de água, mas não evidenciam se o gerenciamento do recurso acontece de maneira a atendê-las.

Gráfico 1 - Demanda por água na Região Hidrográfica Atlântico Leste

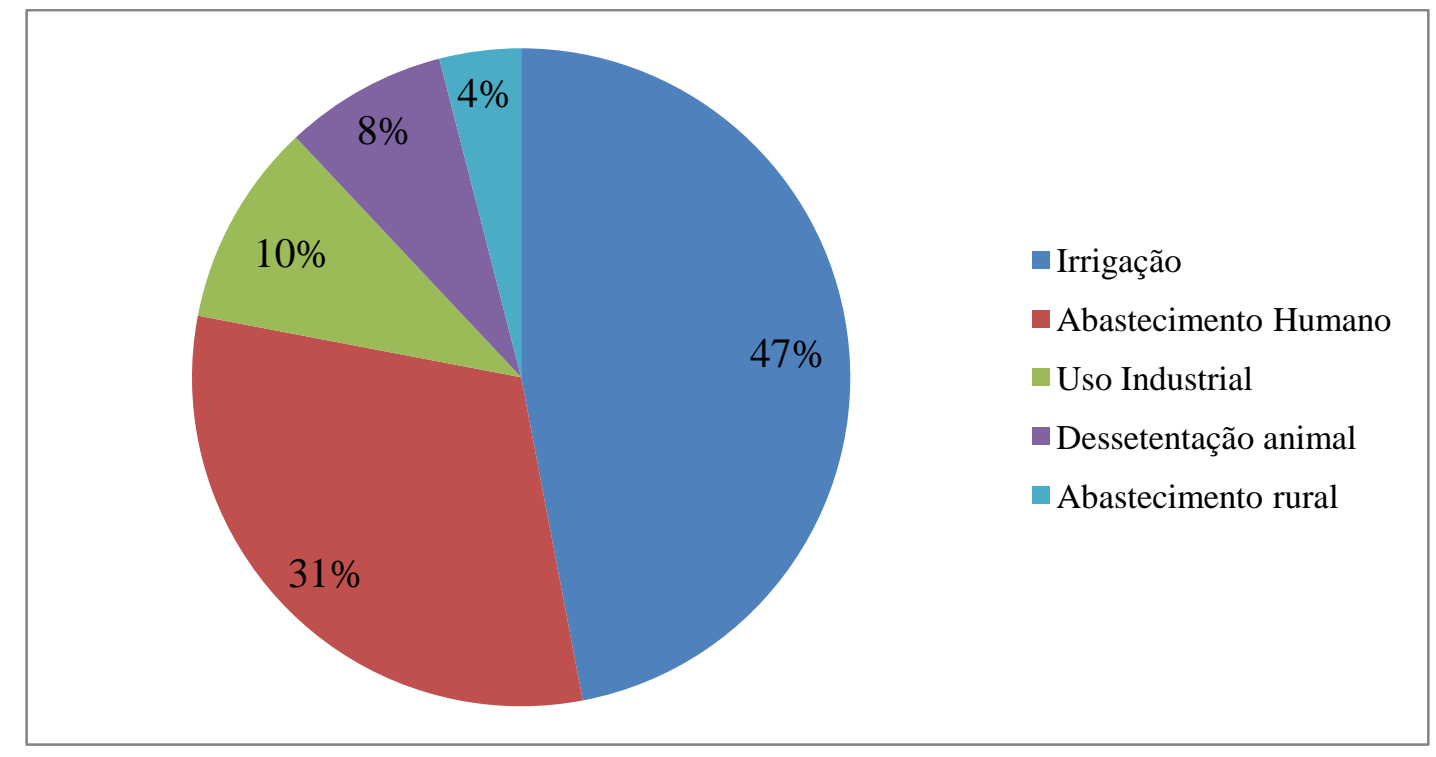

Fonte: ANA (2013)

Devido aos problemas na gestão da água, principalmente, pela falta de acesso ao recurso, surge grande parte dos conflitos, o que reafirma a importância das políticas de regulamentação. Sendo assim, a PNRH direciona, organiza e condiciona o gerenciamento da água no país. 
A região Atlântico Leste se insere na realidade contrastante que ocorre no país, no que se refere a ações sobre gestão e preservação das águas. Acerca disso, constata-se que,

[...] a Bahia possui o Plano Estadual de Recursos Hídricos. Minas Gerais dispõe de planos elaborados para bacias hidrográficas específicas como é o caso dos rios Mucuri, São Mateus, Jequitinhonha e Pardo [...] Os estados do Espírito Santo e de Sergipe já definiram suas Políticas Estaduais de Recursos Hídricos [...] Algumas bacias que integram a Região Hidrográfica como é o caso do rio Itaúnas no Espírito Santo e a do rio Sergipe em Sergipe já têm constituídos seus comitês. (MMA, 2006, 133-134).

Particularmente, na Bahia o gerenciamento do setor se fundamenta no Conselho Estadual de Recursos Hídricos (CONERH), com competências dispostas na Lei 11.612/2009, tendo como órgão executor o Instituto do Meio Ambiente e Recursos Hídricos (INEMA). Os outros Estados possuem ações, como planos para bacias hidrográficas específicas, políticas estaduais de recursos hídricos e também a constituição de comitês, que contribuem para uma gestão integrada dos recursos hídricos.

Portanto, a Região Hidrográfica Atlântico Leste possui relevante diversidade de fatores ambientais, políticos, econômicos e sociais, os quais devem ser levados em consideração na construção de políticas adequadas ao setor de recursos hídricos. Considera-se essencial também a constituição de comitês de bacias, pois só assim será possível pensar em um gerenciamento democrático que considere a demanda e a disponibilidade do recurso água na região.

\section{Considerações finais}

Neste texto, discutiu-se a respeito da Região Hidrográfica Atlântico Leste e a importância da gestão dos recursos hídricos no que se refere à demanda e à disponibilidade de água. Tais aspectos são relevantes no estudo das bacias hidrográficas que compõem a região, pois comporta uma série de elementos que viabilizam o estudo dos aspectos ligados às características físicas, à ação antrópica, como também aos fatores políticos, sociais e econômicos.

Diante do estudo realizado, observou-se que a região envolve territórios de quatro Estados, sendo sua maior parte localizada no semiárido nordestino, ficando perceptível a demanda pelos recursos hídricos em contraponto à sua disponibilidade, o que influencia na 
Bacias hidrográficas e gestão dos recursos hídricos: o caso da Região Hidrográfica Atlântico Leste MATOS, A. S. de; ROCHA, C. R.; OLIVEIRA, M. A. de

disputa pela água entre os setores que a utilizam de maneira consuntiva, ou seja, a irrigação, o abastecimento urbano, o uso industrial, a dessedentação animal e o abastecimento rural.

Vale salientar a importância dos órgãos competentes, como o Conselho Nacional de Recursos Hídricos, a Agência Nacional de Águas, os Comitês de Bacias Hidrográficas, o Ministério do Meio Ambiente e a Secretaria de Recursos Hídricos, no que se refere à preservação e gestão da água, considerando a demanda, disponibilidade e fiscalizando a execução das disposições definidas pelas políticas aplicadas ao setor no Atlântico Leste e nas outras regiões hidrográficas que compõem o território brasileiro.

\section{Referências}

AGÊNCIA NACIONAL DE ÁGUAS. A Evolução da Gestão dos Recursos Hídricos no Brasil. Brasília: ANA, 2002. Disponível em: $<$ http://arquivos.ana.gov.br/institucional/sge/CEDOC/Catalogo/2002/AEvolucaodaGestaodos RecursosHidricosnoBrasil.pdf>. Acesso em: 28 out. 2017.

Conjuntura dos recursos hídricos no Brasil: 2013. Brasília: ANA, 2013.

Disponível em:

<http://arquivos.ana.gov.br/institucional/spr/conjuntura/ANA_Conjuntura_Recursos_Hidricos _Brasil/ANA_Conjuntura_Recursos_Hidricos_Brasil_2013_Final.pdf $>$. Acesso em: 11 nov. 2017.

Conjuntura dos recursos hídricos no Brasil: regiões hidrográficas brasileiras.

Brasília: ANA, 2015. Disponível em:

$<$ http://arquivos.ana.gov.br/institucional/sge/CEDOC/Catalogo/2015/ConjunturaDosRecursos HidricosNoBrasil2015.pdf> . Acesso em: 11 nov. 2017.

Implementação do enquadramento em bacias hidrográficas no Brasil; Sistema nacional de informações sobre recursos hídricos - Snirh no Brasil: arquitetura computacional e sistêmica. Brasília: ANA, 2009. Disponível em:

$<$ http://www.sigrh.sp.gov.br/public/uploads/documents/7504/implementacao-enquadramentoag-superf-ana-2009.pdf>. Acesso em: 28 out. 2017.

BOGDAN, Robert; BIKLEN, Sari. Investigação qualitativa em educação: uma introdução à teoria e aos métodos. Porto, PT: Porto editora, 1994.

BRASIL. Política Nacional de Recursos Hídricos. Lei nº 9.433, de 8 de janeiro de 1997.

CNRH. Resolução n. 32, de 15 de outubro de 2003. Anexo I. Conselho Nacional de Recursos Hídricos. Brasília, DF: Ministério do Meio Ambiente, 2003.

GARCEZ, Lucas Nogueira; ALVAREZ, Guillermo Acosta. Hidrologia. São Paulo: Edgard Blücher, 1998.

LAKATOS, Eva Maria; MARCONI, Marina de Andrade. Fundamentos de metodologia científica. 7. ed. São Paulo: Atlas, 2010. 
MINISTÉRIO DO MEIO AMBIENTE; SECRETARIA DE RECURSOS HÍDRICOS. Caderno da região hidrográfica Atlântico Leste. Brasília: MMA, 2006. Disponível em: <http://www.mma.gov.br/estruturas/161/_publicacao/161_publicacao03032011024710.pdf〉. Acesso em: 02 out. 2017.

Plano Nacional de Recursos Hídricos: Síntese Executiva. Brasília: MMA, 2006.

Disponível em:

<http://www.mi.gov.br/documents/10157/3675235/PLANO+NACIONAL+DE+RECURSOS +HIDRICOS.pdf/>. Acesso em: 29 out. 2017.

OLIVEIRA, Manoel Alves de. Condições ambientais e alterações na paisagem relacionadas à instalação de reservatórios de água na bacia do Rio Gavião - Centro Sul da Bahia. 2012. 246 f. Tese (Doutorado em Geografia) - Universidade Federal Fluminense, Niterói, 2012.

PAULA, João Antonio de. et al. Biodiversidade, população e economia: uma região de Mata Atlântica. Belo horizonte: UFMG/Cedeplar; ECMXC; PADCT/CIAMB, 1997.

ROCHA, Julio Cesar se Sá da. Democracia na gestão das águas: atuação do Conselho Estadual de Recursos Hídricos. Salvador: EDUNEB, 2012. 